\title{
SOFC Long Term Operation in Pure Methane by Gradual Internal Reforming
}

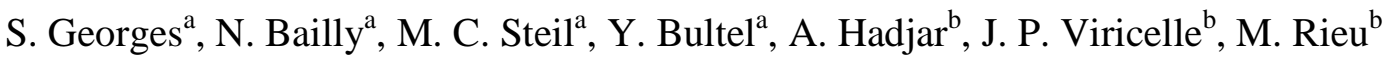 \\ ${ }^{a}$ Laboratoire d'Electrochimie et de Physicochimie des Matériaux et des Interfaces LEPMI, UMR \\ 5279, CNRS - Grenoble INP - Université de Savoie - Université Joseph Fourier BP75, 38402 \\ Saint Martin d'Hères, France \\ ${ }^{b}$ Ecole Nationale Supérieure des Mines, SPIN-EMSE, CNRS:UMR5307, LGF, F-42023 Saint- \\ Étienne, France
}

\begin{abstract}
A solid oxide fuel cell was designed to be operated in pure methane, without reforming or carrier gas. The fuel cell was built up from conventional NiO-YSZ anode supported cell with a specific Pt screen-printed anodic collecting system and a Ir-CGO catalytic layer. The operation principle is based on Gradual Internal Reforming. After an initiation in $\mathrm{H}_{2}$ for 30 minutes, the cell was operated for almost 2000 hours in pure and dry $\mathrm{CH}_{4}$ with a fuel utilization rate of $30 \%$. Intrinsic gradual degradation of $15 \% / 1000 \mathrm{~h}$ was observed, but no coking occurred at the anodic side.
\end{abstract}

\section{Introduction}

The operation of SOFC in different carbon-based fossil fuels (natural gas, syngas) or renewable fuels (biogas, waste fuels, bioethanol), is a huge actual challenge whose success will condition the development and large scale application of fuel cells in the future. The first step to be achieved is the demonstration of stable operation in pure hydrocarbons, with high performances and without need of addition of reforming gas $\left(\mathrm{H}_{2} \mathrm{O}, \mathrm{CO}_{2}, \mathrm{O}_{2} \ldots\right)$ or carrier gas, for simplicity, flexibility, reliability and cost considerations. The demonstration of the robustness of the system in these conditions is essential while the investigation of the other limitations (sulfur poisoning, siloxanes contamination...) is carried out in parallel. If the system is demonstrated to be stable in pure hydrocarbon, the fuel flexibility can then be investigated. SOFC with original cell configurations (anode barrier or catalysts) or new anode materials have been operated or modelled in various hydrocarbons (1-6). In this paper, after definition (7), simulation (89) and experimental demonstration of the Gradual Internal Reforming concept in methane (10-11) and in ethanol (12), we report the design and long term operation in gradual internal reforming of an anode-supported solid oxide fuel cell including a catalytic layer in pure methane. 


\section{Experimental}

The fuel cells were prepared from commercial YSZ/NiO-YSZ (Forschungszentrum Julich) half cells. Composite cathodes, deposited by screen-printing, were made of a LSM:YSZ (60:40) layer, $35 \mu \mathrm{m}$ thick covered by a $15 \mu \mathrm{m}$ thick pure LSM layer annealed in two steps at $1200^{\circ} \mathrm{C}$ in air. An additional gold mesh was screen-printed onto the cathode surface and annealed at $900^{\circ} \mathrm{C}$ in air to improve cathodic collect. The details of the screen-printing process will be found elsewhere (13-14). Deposition and microstructure were optimised up to an ASR of $0.48 \Omega . \mathrm{cm}^{2}$ at $1073 \mathrm{~K}$, using symmetrical cells in air. Due to the configuration of the cell including a catalytic layer on the top of the anode, an original anodic collecting system had to be designed. The development of these original anodic collectors will be detailed in a forthcoming paper. In this study, a Pt mesh shaped anodic current collector was deposited onto the oxidized cermet surface by screen-printing (Aurel, C.890) from commercial ink (ESL 5545) using a mesh 180 mask. A gold ring was fixed and pasted on the top of the mesh using the same ink as the mesh. Two wires were connected to this ring, one for potential monitoring, one for current flow. The annealing was made first at $300^{\circ} \mathrm{C}$ in air for 15 minutes to remove solvants and organics (as indicated by TGA), and then at $900^{\circ} \mathrm{C}$ in $\mathrm{N}_{2}$ for 15 minutes. These thermal treatments were demonstrated in a preliminary study to have no effect on the cathode properties.

The anodic side of the fuel cell was then covered by a $0.1 \mathrm{wt} \%$ Ir-CGO catalyst coating, $200 \mu \mathrm{m}$ thick deposited by 3D controlled spray coating. This optimal thickness was evaluated from simulation studies (8-9). The cell, $19 \mathrm{~mm}$ in diameter with an electrochemically active surface given by the cathode surface of $0.79 \mathrm{~cm}^{2}$, was inserted in a 3 atmospheres setup using an alumina ring. Gas tightness and sealing were achieved using specific glass and gold rings. More details on the experimental setup are available elsewhere (10-11). After glass sealing in air at $860^{\circ} \mathrm{C}$, the anode was gradually reduced in $\mathrm{Ar} / \mathrm{H}_{2}$ mixtures at $800^{\circ} \mathrm{C}$. The $\mathrm{OCV}$ stabilized at $1.13 \mathrm{~V}$. This value, close to the theoretical Nernst potential, confirms the gas tightness of the system. Electrochemical characterisation of the cells was performed into pure or Ar-diluted $\mathrm{H}_{2}$ and/or $\mathrm{CH}_{4}$ with flow rates controlled by calibrated mass flowmeters, using Solartron 1250 frequency response analyser and Solartron 1287 electrochemical interface. The microstructural characterisation was made with a Zeiss Ultra 55 FEG scanning electron microscope.

In this paper, the fuel utilization is assimilated to the faradaïc efficiency as defined by the Faraday's law, considering 2 electrons for $\mathrm{H}_{2}$ and 6 for $\mathrm{CH}_{4}(\mathrm{CO}$ is usually not oxidized at the anode, as demonstrated (10-11).

\section{Results and discussion}

The operation principle of the fuel cell described in this paper, Gradual Internal Reforming with a catalytic layer in dry methane, sketched in figure 1 , is based on the two fastest reactions, self sustained in the system, i.e. electrochemical oxidation of $\mathrm{H}_{2}$ [1] and catalytic steam reforming of $\mathrm{CH}_{4}[2]$. 


$$
\begin{array}{r}
\mathrm{H}_{2}+\mathrm{O}^{2-} \rightarrow \mathrm{H}_{2} \mathrm{O}+2 \mathrm{e}^{-} \\
\mathrm{CH}_{4}+\mathrm{H}_{2} \mathrm{O} \rightarrow \mathrm{CO}+3 \mathrm{H}_{2}
\end{array}
$$

The steam produced by electrochemical oxidation of hydrogen at the triple phase boundaries is used gradually along the fuel stream to complete the catalytic steam reforming of methane in the $0,1 \mathrm{wt} \%$ Ir-CGO catalytic superficial layer (figure 1).

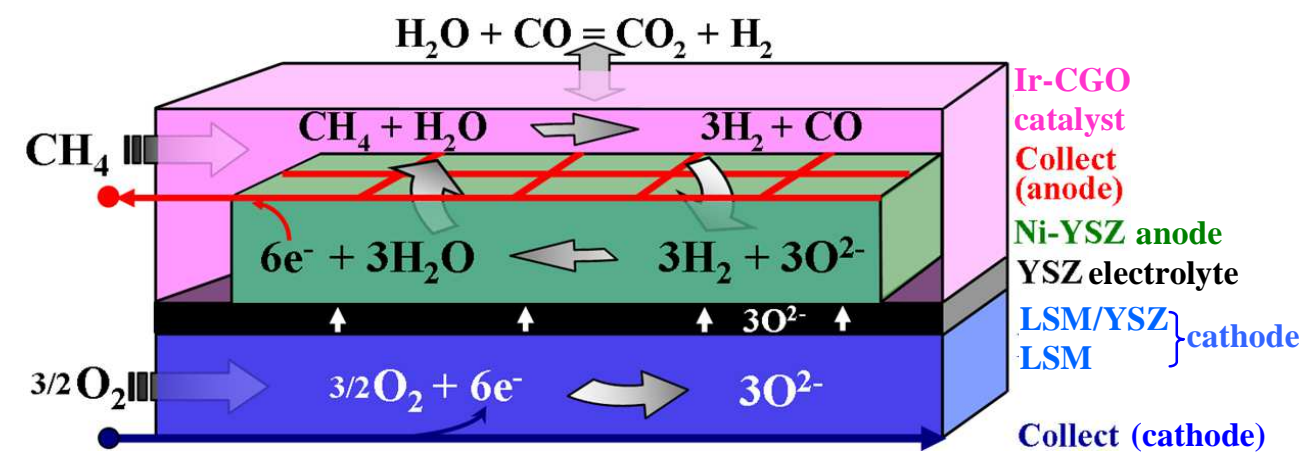

Figure 1. Sketch of the fuel cell architecture and schematic principle of Gradual Internal Reforming associated with Electrocatalytic Decoupling with screen-printed Internal Anodic Collecting System

Under load conditions and at steady state, there is no need of external steam supply if a sufficient quantity is released from the operating anode by [1], and provided that the catalytic reaction of $\mathrm{CH}_{4}$ conversion into $\mathrm{H}_{2}$ and $\mathrm{CO}$ over Ir-CGO catalysts is fast and complete, as already demonstrated (15). Based upon these considerations, looking at [1] and [2] stoichiometry, and without considering carbon monoxide which is not oxidized electrochemically at the anode, as demonstrated by electrochemistry/GPC coupled experiments (11), the simplest model of cell operation consists in assuming that the oxidation following [1] of only one of the three $\mathrm{H}_{2}$ molecules obtained from [2], forms one water molecule. Besides, only one water molecule is needed to ensure the conversion of methane following [2]. In other words, a fuel utilization of 1/3 (based on a global faradaïc efficiency of 1 ) is theoretically sufficient to release enough steam to convert the entire methane stream in the catalyst layer, complete the catalytic reforming reaction, and avoid the contact between $\mathrm{CH}_{4}$ and $\mathrm{Ni}$ (and subsequent carbon cracking). Below 1/3, the system will not release enough steam to ensure itself complete conversion, and methane will diffuse into the cermet yielding fast coking. More details concerning this concept will be found in our previous work (7-12). This simplified principle mechanism was applied here study and the faradaïc efficiency was first optimized in $\mathrm{H}_{2}$ above $1 / 3$ by adjusting the experimental parameters (fuel concentration and flow rates). The gradual consumption of methane following the radial anodic stream (10-11) ensures the delocalisation of the high endothermicity of steam reforming $\left(\Delta \mathrm{H}=206 \mathrm{~kJ} \cdot \mathrm{mol}^{-1}\right)$.

During the first polarisation of the cell, if $\mathrm{CH}_{4}$ is used as the fuel, steam is absolutely required to initiate the catalytic reaction. Without steam (or other reforming gas), methane diffuses into the cermet and yields immediate coking. Consequently, initiation 
was made in $\mathrm{H}_{2}$, as already reported for electrolyte supported cells (10-11). When a steady state is achieved, the continuous steam release allows the direct and abrupt switch from $\mathrm{H}_{2}$ to dry $\mathrm{CH}_{4}$ as the fuel, provided that current (and then steam release) is maintained constant to avoid interruption in the catalytic conversion, $\mathrm{CH}_{4}$ diffusion into the cermet and subsequent coking. During the fuel switch, fuel flows are adjusted in order to provide to the anode a theoretical constant number of electrons considering [2], where only $\mathrm{H}_{2}$ is oxidised (see above). According to [1] and [2], $\mathrm{H}_{2}$ and $\mathrm{CH}_{4}$ give theoretically 2 and $6 \mathrm{e}^{-}$respectively. This hypothesis is confirmed below.

Based upon these considerations, when the fuel was switched from $\mathrm{H}_{2}$ to $\mathrm{CH}_{4}, \mathrm{CH}_{4}$ partial flow rate was divided by 3 to maintain a theoretical number of electrons provided to the anode, and thus maintain the current density. These two basic principles summarized in Figure 1, were applied for the experimental demonstration and durability tests of anode supported cells operating in Gradual Internal Reforming of dry methane with electro-catalytic dissociation in two different layers. The advantages of Gradual Internal Reforming with the use of a catalytic layer (delocalisation of the endothermicity, no water or reforming gas in the fuel, no carbon deposition, performances and durability increase) were already reported (10). The catalytic layer has no electrical function, and the cermet has no catalytic role towards the hydrocarbon conversion. Accordingly, the best materials can be used for each function, leading to the so-called electrocatalytic dissociation principle. In this study, specific anodic current collectors were designed between the anode and the catalyst by screen printing (see figure 1). The development of these collectors using different metals $(\mathrm{Au}, \mathrm{Pt}, \mathrm{Cu})$ will be reported in details in another paper. In particular, neighbouring power densities were obtained in the same conditions (diluted hydrogen) with all of those metals.

A typical polarisation curve obtained at $800^{\circ} \mathrm{C}$ in $\mathrm{H}_{2}\left(2 \mathrm{~L} \cdot \mathrm{h}^{-1}\right)$ with a $\mathrm{Pt}$ screen-printed collector is given in figure 2 .

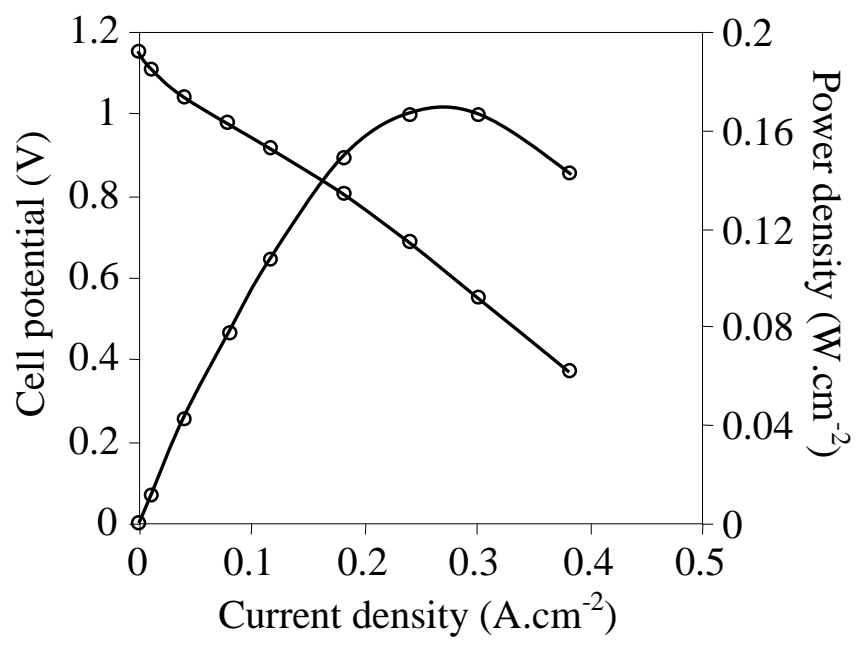

Figure 2. Polarisation curve of the fuel cell with Pt screen-printed anodic collector and catalytic layer obtained in $\mathrm{H}_{2}$ at $800^{\circ} \mathrm{C}$ 
The maximum power density is $0.17 \mathrm{~W} . \mathrm{cm}^{-2}$ at $0.6 \mathrm{~V}$, whereas $0.3 \mathrm{~W} \cdot \mathrm{cm}^{-2}$ $\left(\sim 0.5 \mathrm{~A} \cdot \mathrm{cm}^{-2}\right.$ at $\left.0.6 \mathrm{~V}\right)$ were achieved by increasing the fuel flow rate, but with a lower fuel utilization. The performances of the fuel cell are probably diffusion-limited in a certain proportion by the catalytic layer as pointed out (2), but this aspect was not considered here. Due to the limitations mentioned above, the polarisation curves cannot be recorded in $\mathrm{CH}_{4}$. Accordingly, the fuel utilization was optimised using $\mathrm{H}_{2}$ as the fuel, following the principles described above. This study is summarized in figure $3 \mathrm{a}$ for $\mathrm{Ar}-\mathrm{H}_{2}$ mixtures.
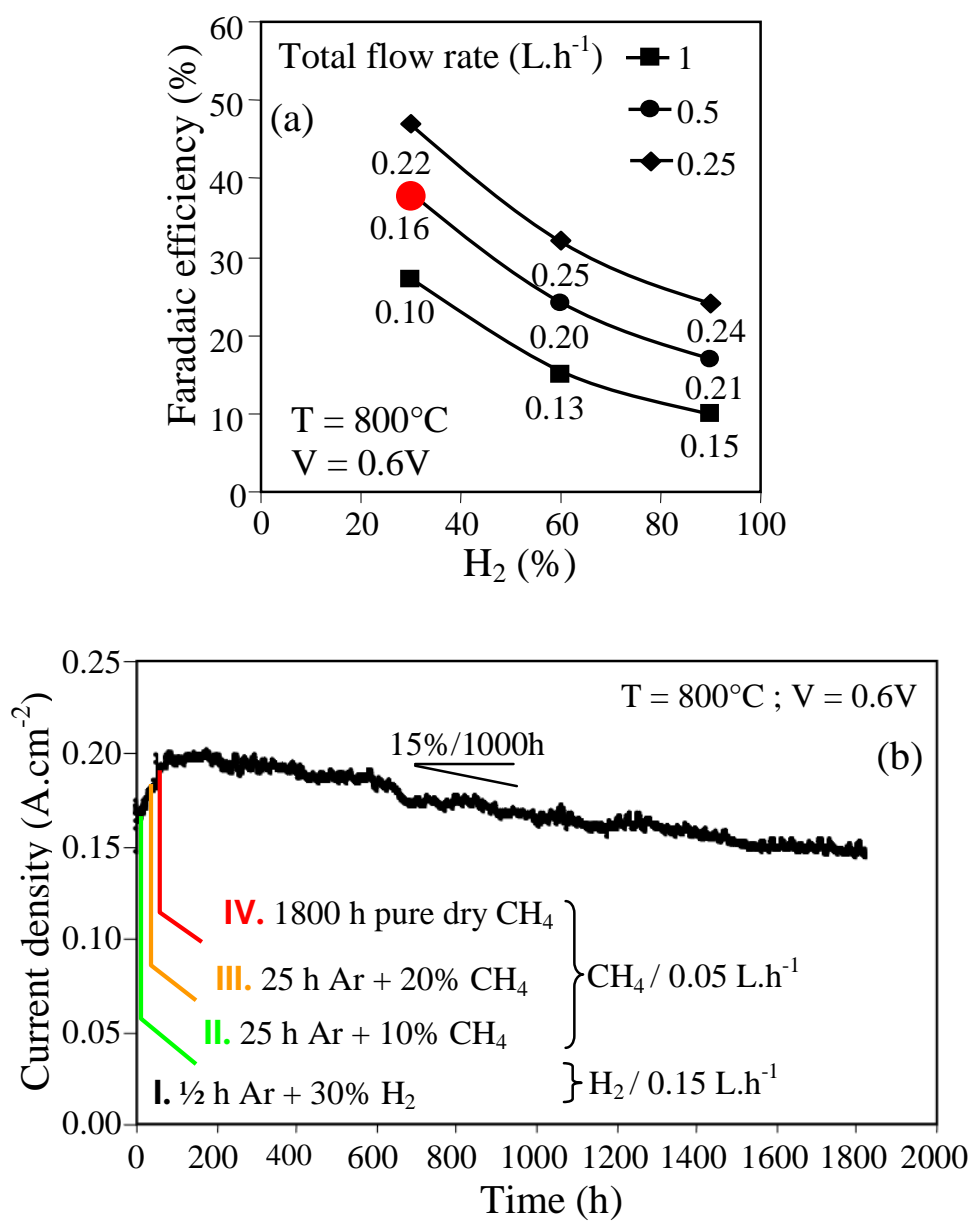

Figure 3. (a) Variation of $\mathrm{H}_{2}$ utilization rate (for a faradaïc efficiency of 1) at $800^{\circ} \mathrm{C}$ in Ar- $\mathrm{H}_{2}$ mixtures as a function of concentration and total flow rate; numbers indicate the current density; the red point shows the operation conditions of the experiment of Figure $3 \mathrm{~b}$; (b) potentiostatic test at $800^{\circ} \mathrm{C}$ and $\mathrm{V}=0,6 \mathrm{~V}$ in pure dry methane for 1800 hours after initiation in $\mathrm{H}_{2}$ and gradual suppression of $\mathrm{Ar}$ (carrier gas)

For a given $\mathrm{H}_{2}$ concentration, the fuel utilization decreases when the flow rate increases, and for a given flow rate, the fuel utilization decreases when $\mathrm{H}_{2}$ concentration increases, in spite of significant increase of the current density. It means that the fuel cell efficiency is better for concentrated fuels with a low flow rate. Here, the best compromise was obtained with a total flow rate of $0.5{\mathrm{~L} . \mathrm{h}^{-1}}^{-}$with $30 \% \mathrm{H}_{2}$ in $\mathrm{Ar}$, i.e. a partial flow rate 
of $0.15 \mathrm{~L} . \mathrm{h}^{-1}$ for hydrogen, yielding fuel utilization of about $38 \%$ and current density of $0.16 \mathrm{~A} . \mathrm{cm}^{-2}$. Using these conditions, long term stable operation in pure methane was achieved. As indicated above, the cell was gradually $\left(0.5 \mathrm{~V} \cdot \mathrm{min}^{-1}\right)$ polarised at $\mathrm{V}=0.6 \mathrm{~V}$ in diluted $\mathrm{H}_{2}$ (figure $3 \mathrm{~b}$ ). After 30 minutes, at steady state, the fuel mixture was turned to 0.05 L. $\mathrm{h}^{-1}$ of methane (i.e. $1 / 3$ of initial $\mathrm{H}_{2}$ flow rate, see above), maintaining a constant total flow rate of $0.5 \mathrm{~L}^{-1} \mathrm{~h}^{-1}\left(10 \% \mathrm{CH}_{4}\right)$ for 25 hours (see figure $3 \mathrm{~b}$ ).

After this fuel switch, The current density remained almost at its previous value, which confirms the choice of the $1 / 3$ ratio related to the $6 \mathrm{e}^{-}$provided by $\mathrm{CH}_{4}$ (see above). After a second step of 25 hours with $20 \% \mathrm{CH}_{4}$ (with a constant $\mathrm{CH}_{4}$ partial flow rate) $\mathrm{Ar}$ was suppressed. Methane flow rate was manually adjusted for another 30 minutes to maintain a constant current density. The increase of the current density when the concentration of the fuel is increased is consistent with the behaviour observed in figure $3 \mathrm{a}$ in hydrogen. The increase of $\mathrm{CH}_{4}$ concentration increases the fuel utilisation. The cell was then left for 1800 hours in pure methane (figure 3b). A gradual linear decrease of the performances of $15 \% / 1000 \mathrm{~h}$. was observed. It is to be mentioned that with this degradation, the fuel utilization was slightly below the $1 / 3$ theoretical limit. The cell was unfortunately stopped after 1800 hours $\left(2 \frac{1}{2}\right.$ month) of continuous operation for plant power supply maintenance. The shut down was made following the invert procedure. The fuel was turned to $\mathrm{H}_{2}$, maintaining the current density, left for 24 hours and then gradually depolarized. No carbon was observed at the anode or detected by EDX, no degradation of the anodic components could be observed (see figure 4).

The catalyst layer delaminated during the cell cooling and disassembly. The screenprinted Pt collector shows a very close contact with the cermet nickel, but no degradation of the components or interfaces can be evidenced from figure 4. The main modification was observed at the surface of the grains and along the grain boundaries of the electrolyte, with the apparition of sub-micrometric cracks and pores.

The degradation of the performances was then tentatively attributed to intrinsic ageing, mainly due to gradual increase of the electrolyte ohmic losses, as already mentioned for YSZ electrolysis cells long term operation (16) with higher current density, and evidenced by SEM as the presence of nanoporosity in YSZ grains, together with connexion loss in between grains. Ageing of the test bench, especially of the sealing glass can also explain this significant degradation.

Complete cell design procedure, operation and post-mortem analysis will be reported in a forthcoming paper. 


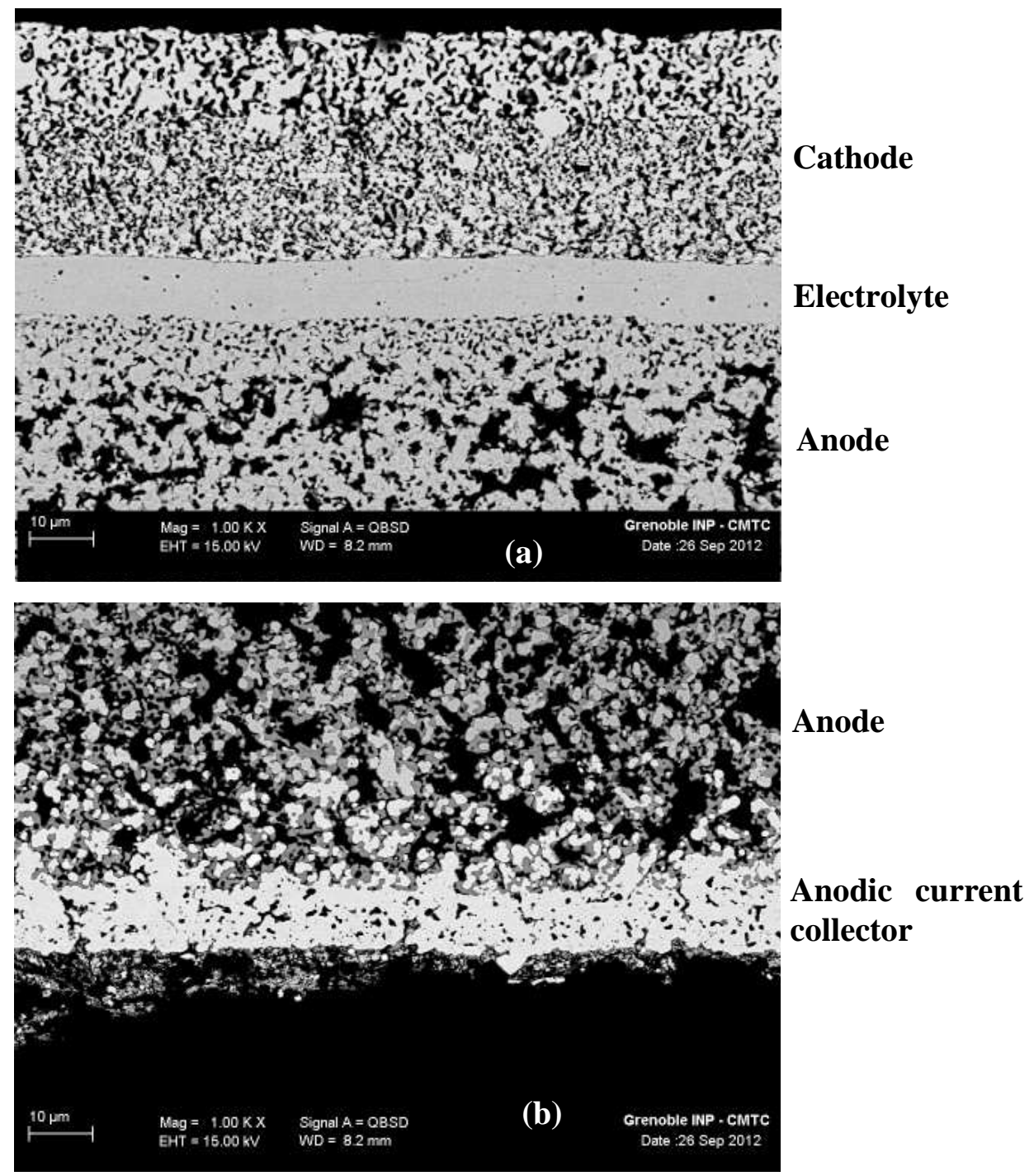

Figure. 4: SEM micrographs after 1800 hours in pure $\mathrm{CH}_{4}$ of the complete cell (a); Detail of the anodic current collector

\section{Conclusion}

This study demonstrates the ability of SOFC systems with decoupled electrochemical and catalytic components and functions, to operate durably in pure methane without supply of reforming gas by Gradual Internal Reforming, provided that the following conditions are respected:

- Initiation of operation and then steam release without carbon (in $\mathrm{H}_{2}$ for example)

- Adjustment of the flow rates $\mathrm{H}_{2} / \mathrm{CH}_{4}$ to maintain the current density

- Optimization of the fuel utilization, to prevent carbon deposition conditions 
This architecture allows the use of the best anode and catalyst at the same time. These results open the perspectives of fuel flexibility for SOFC. Demonstration has already been made for $\mathrm{H}_{2} / \mathrm{CH}_{4} / \mathrm{C}_{2} \mathrm{H}_{5} \mathrm{OH}[6]$.

\section{Acknowledgments}

The authors acknowledge ADEME (program MACSOFC 0874C0130) and GDF SUEZ for grant and financial support

\section{References}

1. Park S., Vohs J. M., Gorte R. J., Nature, 404, 265 (2000)

2. Zhan Z., Barnett S. A., Science, 308, 844 (2005)

3. E. S. Hecht, G. K. Gupta, H. Zhu, A. M. Dean, R. J. Kee, L. Maier, O. Deutschmann, Applied Cat. A: General 295, 40 (2005)

4. K. Nikooyeh, A. A. Jeje, J. M. Hill, J. Power Sources, 171, 601 (2007)

5. N. Laosiripojana, S. Assabumrungrat, J. Power Sources, 163, 943 (2007)

6. Y. Wang, F. Yoshiba, M. Kawase, T. Watanabe, Intl. J. of Hydrogen Energy, 34, 3885 (2009)

7. Vernoux P., Guindet J., Kleitz M., J. Electrochem. Soc., 145 (10), (1998)

8. J-M. Klein, S. Georges and Y. Bultel, J. Electrochem. Soc., 155(4), B333 (2008) B333-B339

9. J. M. Klein, S. Georges, Y. Bultel, J. Applied Electrochemistry, 40, 943 (2010)

10. J-M. Klein, M. Hénault, Y. Bultel, P. Gélin and S. Georges, Electrochemical and Solid State Letters 11(8), B144 (2008)

11. J-M. Klein, M. Hénault, C. Roux, Y. Bultel and S. Georges, J. Power Sources, 193, 331 (2009)

12. S. D. Nobrega, M. V. Galesco, K. Girona, D. Z. de Florio, M. C. Steil, S. Georges, F. C. Fonseca, J. Power Sources, 213, 156 (2012)

13. D. Rotureau, J-P. Viricelle, C. Pijolat, N. Caillol, M. Pijolat, J. of Eur. Ceram. Soc, 25, 2633 (2005)

14. J-P. Viricelle, S. Udroiu, G. Gadacz, M. Pijolat, C. Pijolat, Fuel Cells, 10 (4), 683 (2010)

15. Gélin P., Belatel H., Kaddouri A., Catalysis Today, 157 (1-4), 451 (2010)

16. Tietz F., Sebold D., Brisse A., Schefold J., J. Power Sources, 223, 129 (2013) 